\title{
Social anxiety and attentional biases: A top-down contribution?
}

\author{
Hannah L. Boal $^{1}$ • B. K. Christensen ${ }^{1}$ - S. C. Goodhew ${ }^{1}$
}

Published online: 8 September 2017

(C) The Psychonomic Society, Inc. 2017

\begin{abstract}
Selective attention toward threatening facial expressions has been found to precipitate and maintain symptoms of social anxiety. However, the automaticity of this bias is under debate. In the present study, we aimed to test whether top-down (controlled) engagement and disengagement of attention toward threatening faces is associated with social anxiety. This was examined by testing the impact of a secondary working memory (WM) load on attentional biases. In a variation of the dot-probe task, participants' attention was initially cued to the left or right of fixation before an upright face paired with an inverted face was presented (displaying a disgust or neutral expression), and participants responded to a subsequently presented probe. The task was performed under no-load, low-load (one-digit memory task), and high-load (six-digit memory task) conditions. Social anxiety was not found to be associated with delayed disengagement from threat. However, surprisingly, high social anxiety was associated with an engagement bias away from threat, whereas low social anxiety was associated with a bias toward threat. These results were unaffected by the WM load manipulation. This indicates that engagement with threatening facial expressions has minimal contributions from top-down mechanisms, since it is likely that orienting to facial expressions occurs relatively automatically.
\end{abstract}

Keywords Selective attention - Spatial attention - Working memory load $\cdot$ Social anxiety $\cdot$ Dot-probe

Hannah L. Boal

Hannah.boal@anu.edu.au

1 Research School of Psychology, Australian National University, (Building 39), Canberra, ACT 2601, Australia
When interacting with our environment, we are bombarded with visual information, only a small amount of which can be consciously processed due to our limited perceptual resources (Desimone \& Duncan, 1995; Kastner \& Pinsk, 2004). Selective attention is, therefore, used to filter information so that the visual system can preferentially attend to important and relevant aspects of the visual environment. Consequently, selective attention is integral in shaping our perception of the world around us. One factor that exerts a powerful influence over selective attention is an individual's level of anxiety. For example, although healthy individuals may show a small bias for preferentially processing threatening stimuli (e.g., feared objects such as snakes) over neutral stimuli, this bias is heightened for individuals with anxiety. Indeed, this threat bias is viewed as a core cognitive component of anxiety and is central to many contemporary conceptualizations of clinical anxiety disorders and their treatments (Cisler \& Koster, 2010). For example, some longitudinal studies suggest that threat biases in childhood predict the development of anxiety disorders later in life (Shechner et al., 2012). Furthermore, threat biases are involved in the maintenance of anxiety, since attentional training to reduce threat biases also reduces anxiety (for a review, see Bar-Haim, 2010).

Given the sensitivity of socially anxious individuals to negative social evaluation, threatening facial expressions hold special clinical significance for this population (Rapee \& Heimberg, 1997). According to Rapee and Heimberg's cognitive model, individuals with social anxiety are hypervigilant to monitoring their external environment for signs of negative evaluation from others. For example, when giving a speech, a socially anxious individual will be more likely to scan their audience for facial signs of criticism or disapproval (e.g., frowning), which then increases their level of anxiety. This model is supported by research findings that socially anxious individuals show biased attention toward photos depicting 
angry, hostile, and disgust expressions compared with neutral facial expressions (Mogg, Philippot, \& Bradley, 2004; Pishyar, Harris, \& Menzies, 2004).

In the present study, we aimed to test whether these threat biases are driven by bottom-up or top-down attention. Topdown attention refers to the voluntary allocation of attention toward particular objects, features, or spatial locations on the basis of one's current goals. For example, when looking for a friend in a crowd, knowing that the friend is wearing a red scarf allows one to selectively attend to red objects. By contrast, bottom-up attention is an involuntary, rapid, and inflexible process that selects visual information on the basis of the salience of the stimulus features. For example, while searching for a red object, an individual's attention may be captured by a flashing billboard even though the person had no intention to attend to that stimulus.

Traditionally, threat biases have been conceptualized as bottom-up. In line with this notion, evolutionary models posit that being able to respond to threat through bottom-up processing is adaptive (Kenrick, Neuberg, Griskevicius, Becker, \& Schaller, 2010; Lang, Bradley, \& Cuthbert, 1997; LeDoux, 1996; LoBue, Rakison, \& DeLoache, 2010; Mogg \& Bradley, 1998; Öhman, 2007). That is, being able to detect a threatening stimulus in the environment has evolved in the human species to facilitate survival (e.g., a fight or flight response to a predator) and is part of an automatic vigilance mechanism (Pratto \& John, 1991). In support of this argument, research has shown that humans can engage early and rapid detection of low-level perceptual features associated with threatening images (LoBue, 2014; LoBue \& DeLoache, 2011; LoBue \& Larson, 2010). For example, using a visual search task, LoBue (2014) observed a bias toward curvilinear shapes (representative of snakes) compared with rectangular shapes. In addition, this bias to curvilinear shapes increases after watching a fearful film clip (LoBue, 2014), indicating that anxiety increases the detection of threat-relevant, low-level perceptual features. Similarly, biases for angry face features, such as the downward "V" shape of the eyebrows, have been found in both child and adult populations, which these authors argue indicates an evolved attentional bias for threatening stimuli (LoBue \& Larson, 2010).

However, in opposition to this argument, research has found that threat detection does not always occur automatically. Visual search requires participants to detect an object or feature as rapidly as possible amongst distractor objects in a visual array. Using this task, past research has found that socially anxious individuals detect angry faces among neutral distractors more rapidly than happy faces among neutral distractors (Gilboa-Schechtman, Foa, \& Amir, 1999). However, search times have been found to increase with added distractors (Eastwood, Smilek, \& Merikle, 2001; Öhman, Lundqvist, \& Esteves, 2001). Since automaticity in visual search has traditionally been conceptualized as being invariant to the number of distractors in the display (Treisman \& Gelade, 1980), this suggests that the processing of threatening faces is not purely bottom-up as it requires attentional resources (Pessoa, McKenna, Gutierrez, \& Ungerleider, 2002; Vuilleumier \& Righart, 2011).

The involvement of attentional resources in this process of orienting toward threat can be assessed with the use of working memory (WM) load. Previous research has found that tasks with high WM loads result in greater interference effects from visual distractors compared with low WM load tasks (de Fockert, Rees, Frith, \& Lavie, 2001). Thus, voluntary, topdown selective attention can be impaired by WM load. By contrast, bottom-up attention is unaffected by WM load (e.g., Jonides, 1981). In the present study, therefore, we imposed a WM load to selectively impair the top-down attentional system without impacting bottom-up mechanisms.

Researchers employing WM load tasks have found some evidence that attentional biases can be overcome under high WM load (Pessoa et al., 2002; Van Dillen \& Koole, 2009). For instance, Van Dillen and Koole employed an interference paradigm, in which participants viewed faces of varying expressions and were asked to indicate the gender of the faces. This study showed that, as compared with happy faces, angry faces resulted in slower gender naming, but only under low load. These researchers proposed that, under high load, negative stimuli do not capture attention because WM is fully engaged by the task. Only under low load, when there are spare attentional resources, can negative stimuli be prioritized. However, this body of research has looked at interference effects from threatening stimuli that are presented individually at an attended location, rather than at the capture of attention to the spatial location of a stimulus that is in competition with other stimuli elsewhere in the scene. Spatial attentional capture is particularly important to understanding threat biases for socially anxious individuals as they may cause individuals, when giving a speech for example, to attend to threatening faces in a top-down fashion, thus increasing their anxiety.

Recently, Judah, Grant, Lechner, and Mills (2013) assessed the top-down nature of the threat bias with socially anxious individuals by presenting participants with images of happy, disgust, and neutral facial expressions in a dot-probe task under three conditions: no, low, and high WM load. In the modified dot-probe task, two faces (e.g., one neutral and one negative) are presented on the computer screen, one to the left and one to the right of fixation. A probe (e.g., a letter) is then presented in the locus of one of the faces and participants are asked to respond to its identity. Faster reaction times (RTs) to respond to a probe appearing in the locus of a negative facial expression than to a probe in the locus of a neutral facial expression indicate that participants' attention was captured by the negative face. This is known as a threat bias.

Judah et al. (2013) used a long presentation time for the faces $(1,000 \mathrm{~ms})$, which they claimed measured later 
attentional mechanisms of disengagement and avoidance. These researchers found that socially anxious individuals displayed avoidance of disgust expressions under no WM load but had difficulty disengaging attention under high WM load. However, one issue with this study, and that of the dotprobe design more generally, is that engagement and disengagement biases are conflated. Therefore, a threat bias can arise either due to enhanced engagement with that face or delayed disengagement from it. Although Judah et al. claimed that disengagement biases can be assessed using a long presentation time, this assumes that all participants initially shift their attention equally toward the threatening stimulus. If, however, individuals with higher levels of socially anxiety more readily engage with the threatening face, any attempt to measure the disengagement bias is conflated with engagement effects. Due to this issue, it cannot be determined whether the finding that social anxiety is linked to a threat bias is due to enhanced engagement or delayed disengagement effects.

Grafton and MacLeod (2014) and Rudaizky, Basanovic, and MacLeod (2014) have developed an elegant method for differentiating engagement biases from disengagement biases by using a variation of the dot-probe task. In this design, on each trial participants viewed a target image (a threatening or neutral scene) paired with a non-representational image (abstract art) and participants' shifts of attention toward and away from the location of the target image was measured. Specifically, these researchers presented an initial cue (a small red line oriented horizontally or vertically) before the presentation of the faces. This cue was presented either on the left or right side of the screen and, therefore, secured participants' attention in the same location or opposite location to the target image. A disengagement trial was defined as a trial in which the target image was presented in the same location as the preceding cue, as participants were required to disengage their attention from the target to respond to a subsequent probe in the distal location. An engagement trial, by contrast, was defined as a trial in which the target was presented in the opposite location to the preceding cue, as these trials measured whether participants shifted their attention toward the target. After the cue and faces were presented, a probe (similar in appearance to the cue) was presented in the locus of one of the faces and participants were asked to indicate whether the probe was the same or a different orientation to the cue. On $50 \%$ of trials, the probe appeared in the distal location to the target face and on 50\% of trials, it appeared in the proximal location. Therefore, for engagement trials, faster RTs in the proximal probe position compared with the distal position, indicated that participants shifted their attention toward the target face. Importantly, these distal-proximal probe difference scores were compared between trials in which the target image was negative compared with when it was neutral, to measure if greater engagement toward threat occurred for anxious participants. Similarly, difference scores were used to measure the disengagement bias to test whether participants had greater difficulty shifting away from the target image and responding to the distally presented probe, compared with the proximal probe, when a negative target image was used compared with a neutral target image. Both Grafton and MacLeod (2014) and Rudaizky et al. (2014) found that high trait anxious participants, compared with low trait anxious participants, have engagement biases and delayed disengagement biases for threat.

Although it was published after data collection for the present study was complete, a recent study employed a similar design to measure engagement and disengagement biases for participants with low and high social anxiety (Grafton \& MacLeod, 2016). On each trial, negative and neutral faces were paired together and these researchers found that participants with high social anxiety had a greater engagement bias toward negative facial expressions compared with participants with low social anxiety. Social anxiety was not found to be associated with difficulties disengaging from threat. These data indicate the importance, therefore, of differentiating these biases from one another. The present study will extend on Grafton and MacLeod's (2016) research by testing whether these biases are driven by top-down or bottom-up attentional orienting (Corbetta \& Shulman, 2002; Posner, 1980). Specifically, the present study includes an additional WM load task to test if attentional biases are affected by high WM load, which would indicate that they are driven by top-down attention.

\section{Present experiment}

In the present study, we sought to investigate the contribution of top-down attention in the selective processing of threatening visual information for individuals with high social anxiety. This was tested using a variation of the dot-probe task (Grafton \& MacLeod, 2014; Rudaizky et al., 2014), in which participants were presented with neutral and disgust facial expressions and their engagement with and ability to disengage from these faces were measured. The dot-probe task provides an opportunity to measure spatial attention, which is of particular clinical relevance to social anxiety and also allows for the separate analysis of engagement and disengagement biases. Engagement and disengagement biases were compared under three conditions: no WM load, low WM load, and high WM load. WM load was used to deplete top-down attentional resources. Under no and low WM load, it was expected that higher social anxiety would be associated with an engagement bias toward the disgust faces. If the engagement bias is driven by bottom-up attention, this bias would be unaffected by the load manipulation. However, if the engagement bias is driven by top-down attention, this bias would be attenuated under high WM load. Regarding disengagement 
effects, recent research has shown that social anxiety is not associated with delayed disengagement from threat (Grafton $\&$ MacLeod, 2016). However, trait anxiety, which shares many features with social anxiety, has been found to be associated with delayed disengagement from threat (Grafton \& MacLeod, 2014; Rudaizky et al., 2014). With this study, therefore, we aimed to elucidate whether social anxiety is associated with delayed disengagement from threat and, if it is, whether it is affected by WM load.

\section{Method}

\section{Participants and design}

One hundred participants ( 53 female, 47 male) were recruited from the Australian National University via online advertisement and the university electronic sign-up system and these participants completed the experiment in exchange for course credit or $\$ 30$ payment. Participants all reported to have normal or corrected vision, their ages ranged from 17 to 36 years $(M=$ 22.43, $S D=3.62$ ) and 91 of them were right-handed. Participants' social anxiety scores, as measured by the Social Interaction Anxiety Scale (SIAS; Mattick \& Clarke, 1989), ranged from 3 to $64(M=26.18, S D=12.94)$. These scores are somewhat higher than would be expected on the basis of the normative data of Heimberg, Mueller, Holt, Hope, and Liebowitz (1992), who found a mean of 19.9 on the SIAS in a community sample. Heimberg et al. defined the clinical cutoff for social phobia as being equal to or greater than 34 on the SIAS, which reflected one $S D$ above the mean score of the community sample.

Participants' depression scores on the depression component of the Depression Anxiety Stress Scales (DASS; Lovibond \& Lovibond, 1995) ranged from 0 to 39 ( $M=$ $5.69, S D=5.79)$, and as measured with the State-Trait Anxiety Scale (STAI; Spielberger, Gorsuch, Lushene, Vagg, \& Jacobs, 1983), state anxiety ranged from 20 to $62(M=33.7$, $S D=9.21)$, and trait anxiety ranged from 24 to $72(M=42.55$, $S D=9.06$ ). All participants provided written informed consent prior to participation and provided demographic information. Table 1 presents demographic information and selfreport scores for participants with low and high social anxiety, as calculated using a median split.

\section{Images}

Images of faces was taken from the FACES database (Ebner, Riediger, \& Lindenberger, 2010), consisting of the neutral and disgust expressions from Set $\mathrm{A}$ of the young age range (ages 19-31). Since research has found a same-age facial recognition bias (Rhodes \& Anastasi, 2012), the young age range faces were included in this study to match the average age of the participants. On each trial the two faces presented were taken from the same face model so that they were matched for facial properties, and one image was presented upright and one image was inverted. Each image subtended $6.81^{\circ} \times$ $8.52^{\circ}$ of visual angle.

\section{Experimental task}

Participants completed the demographic questions, SIAS, STAI, and depression items from the DASS, and then participated in the computer task. This experiment was conducted in a dimly lit room. Stimuli were presented on a cathode-ray tube gamma-corrected monitor running at a $75-\mathrm{Hz}$ refresh rate. The viewing distance was set with a chinrest at $44 \mathrm{~cm}$. The stimuli were programmed in MATLAB using the Psychophysics Toolbox (Brainard, 1997), and the background was set to black.

The computer task consisted of three blocks of trials (no load, low load, and high load) counterbalanced across participants. Each block consisted of 224 trials, so each participant completed a total of 672 trials. Before each block, participants completed five practice trials with corrective feedback.

In the low- and high-load conditions, a number was presented centrally on the screen at the beginning and end of each trial (see Fig. 1). A single-digit number was used in the lowload condition, and a six-digit number was used in the highload condition. The digits in these numbers could range between 1 and 9 and were generated using a random number generator. On approximately half of the trials the number presented at the end of the trial matched the one presented at the beginning, and on approximately half of the trials it changed. In the high-load condition, the number could only change by one of the digits, so the participant was required to remember all six digits to determine whether the number was the same or different. For the low-load task the single-digit number was presented for $1,000 \mathrm{~ms}$, whereas in the high-load task the sixdigit number was presented for 3,000 ms, which provided sufficient time to read the number strings. Participants were

Table 1 Demographic and self-report scores for the low and high social anxiety groups

\begin{tabular}{|c|c|c|c|c|c|c|}
\hline & Participants (Female) & Age $M(S D)$ & SIAS $M(S D)$ & DASS-D $M(S D)$ & STAI-S $M(S D)$ & STAI-T $M(S D)$ \\
\hline Low social anxiety & $50(26)$ & $22.26(3.39)$ & $15.72(5.65)$ & $3.66(3.86)$ & $30.10(7.00)$ & $36.54(7.47)$ \\
\hline High social anxiety & $50(27)$ & $22.40(3.66)$ & $36.64(9.10)$ & $7.72(6.67)$ & $37.30(9.79)$ & $46.56(8.79)$ \\
\hline
\end{tabular}




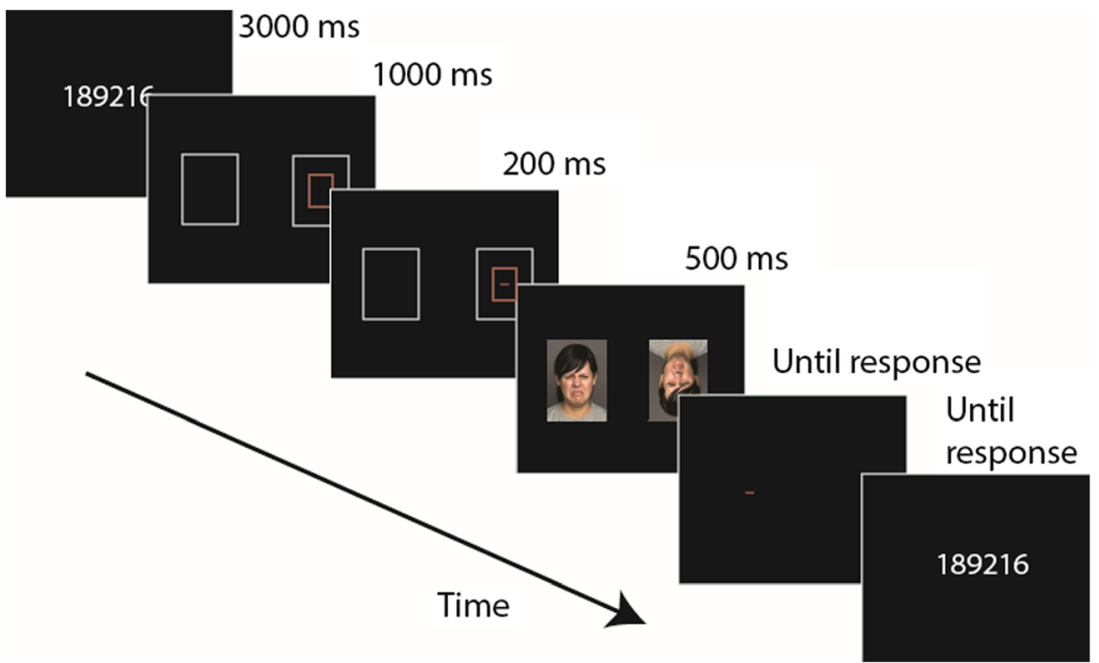

Fig. 1 Schematic of an engagement trial under high load

then asked to make a same/different keyboard press to indicate whether the number matched the one presented at the beginning of the trial.

Regarding the main probe task, initially a blank screen was presented for 1,000 ms. On each trial, two white rectangular outlines were initially presented, one to the left and one to the right of fixation, for $1,000 \mathrm{~ms}$. These rectangular outlines subtended $6.81^{\circ} \times 8.52^{\circ}$ of visual angle, and the width of the lines subtended $0.089^{\circ}$. A smaller red rectangle, subtending $1.70^{\circ} \times 2.13^{\circ}$, was also presented inside one of the white rectangles to indicate the location of the to-bepresented cue. The cue (a small red line) was then presented within the box for $200 \mathrm{~ms}$. This cue could be oriented horizontally or vertically; it subtended a visual angle of $0.48^{\circ}$ and had a width of $0.089^{\circ}$.

After these stimuli disappeared, two images of faces were presented for $500 \mathrm{~ms}$, one to the left and one to the right of fixation, such that they occupied the locations that the white rectangles previously occupied. After these faces had offset, a probe (a small red line) oriented horizontally or vertically, which was identical in appearance to the cue, was then presented at the locus of one of the faces and was oriented horizontally or vertically. Participants made a keyboard press as quickly and accurately as possible to report whether the orientation of the probe matched the orientation of the cue. The variables (location, orientation, and image type) were randomized, with the restriction that equal numbers of trials consisted of disengagement and engagement trials, negative and neutral upright photos, and trials on which the probe was distal or proximal to the upright image.

An engagement trial was defined as a trial in which the upright face was presented in the location opposite from the preceding cue (for a discussion, see Rudaizky et al., 2014). This is because these trials measured the likelihood that participants would shift their attention toward the upright face.
By contrast, for disengagement trials, the upright face was presented in the same location as the preceding cue. Therefore, participants were required to disengage their attention from the upright face to respond to a subsequent probe in the distal location.

Calculation of bias indices In accordance with the method developed by Grafton and MacLeod (2014) and Rudaizky et al. (2014), engagement bias and disengagement bias indices were calculated. Higher scores for the attentional engagement bias index reflect facilitated attentional orienting toward the disgust expression as compared with the neutral expression. The equation is as follows:

Engagement bias index $=($ Cue probe distal to upright negative image in upright negative/inverted image pair: RT for target probes distal to upright negative image minus RT for target probes proximal to upright negative image) minus (Cue probe distal to neutral upright image in neutral upright/inverted image pair: RT for target probes distal to upright neutral image minus RT for target probes proximal to upright neutral image).

Similarly, higher scores for the attentional disengagement bias index reflects greater difficulty disengaging from the disgust expression compared with the neutral expression. The equation is as follows:

Disengagement bias index $=($ Cue probe proximal to upright negative image in upright negative/inverted image pair: RT for target probe distal to upright negative image minus RT for target probe proximal to upright negative image) minus (Cue probe proximal to upright neutral image in upright neutral/inverted image pair: RT 
for target probe distal to upright neutral image minus RT for target probe proximal to upright neutral image).

\section{Results}

The data from two participants were excluded due to technical failure. A further participant's data were excluded due to responding quicker than $100 \mathrm{~ms}$ throughout the experiment, indicating random responding. Finally, three participants' data were excluded because their overall RTs were slower than 3.29 SDs from the average. Therefore, 94 participants' data were included in the further statistical analyses.

The mean accuracies on the probe task were $94.96 \%$ ( $S D=$ $3.47)$ in the no-load condition, $96.89 \%(S D=2.72)$ in the lowload condition, and $96.08 \%(S D=2.83)$ in the high-load condition. The mean accuracy on the digit-span task was significantly $[t(93)=7.10, p<.001]$ higher in the low-load condition $(M=94.56 \%, S D=4.17)$ than in the high-load condition $(M=$ $89.94 \%, S D=7.79$ ), indicating that, as expected, the six-digit task was more difficult than the one-digit task.

Data from trials on which participants performed incorrectly on the probe task were excluded from the analyses, because this indicated that participants were not attending in the correct location at the beginning of the trial. In addition, in the low- and high-load conditions, trials on which participants responded incorrectly on the digit task were excluded, because the load manipulation might not have been successful on these trials. Further exclusions were made of trials on which RTs were less than $100 \mathrm{~ms}$ or greater than $2.5 \mathrm{SDs}$ above the individual participant's mean RT. Each participants' mean performance was then calculated for each condition. The average percentages of excluded trials were $7.60 \%$ for the no-load condition, $13.26 \%$ for the low-load condition, and $18.20 \%$ for the high-load condition.

\section{Engagement bias}

Since the construct of social fear is a continuous variable in the population (McNeil, 2010), social anxiety was analyzed as being continuous in this study. Furthermore, since engagement and disengagement biases are separate attentional processes (Grafton \& MacLeod, 2014), they were analyzed separately. Using the engagement bias index equation, each participant's engagement bias was calculated. To analyze the engagement bias, a repeated measures analysis of covariance (ANCOVA) was performed with the within-subjects variable of load (no, low, and high) and the continuous variable of social anxiety. Mauchley's test indicated that the assumption of sphericity had been violated for load $\left[\chi^{2}(2)=15.53, p<.001\right]$, and therefore degrees of freedom were corrected using the GreenhouseGeisser estimate of sphericity $(\varepsilon=.86)$.
Load was not found to have a significant effect $[F(1.73,91)$ $\left.=0.85, p=.416, \eta_{\mathrm{p}}{ }^{2}=.009\right]$, which indicates that the engagement bias index did not alter across the no-load, low-load, and high-load conditions. In addition, the interaction between load and social anxiety was not significant $[F(1.73,91)=0.64, p=$ $\left..507, \eta_{\mathrm{p}}{ }^{2}=.007\right]$. However, a significant trend effect was found for the relationship between social anxiety level and the engagement bias index $\left[F(1,92)=3.12, p=.081, \eta_{\mathrm{p}}{ }^{2}=\right.$ .033]. Scatterplots revealed that, surprisingly, the engagement bias index decreased with increasing levels of social anxiety. To quantify the effect, a median split was conducted to compare participants with low versus high social anxiety. The participants with low social anxiety had a mean engagement bias index of $4.97 \mathrm{~ms}$ and those with high social anxiety had a mean engagement bias index of $-6.61 \mathrm{~ms}$. This indicates that low social anxiety was associated with a slight bias toward disgust expressions, and high social anxiety was associated with a slight bias away from disgust expressions. The raw data are presented in the Appendix.

Post-hoc exploratory analyses Due to past research indicating that people rapidly habituate to threatening images (Breiter et al., 1996; Staugaard, 2009), we hypothesized that the threat bias might have diminished over the course of the experiment. To further elucidate the trend engagement effect found in the previous analysis, the data from each participant's first block (224 trials) of data were analyzed. An ANCOVA was performed with the between-subjects variable of load (no, low, and high) and the continuous predictor variable of social anxiety. The main effect of load was not significant $[F(2,90)=$ $\left.1.51, p=.227, \eta_{\mathrm{p}}{ }^{2}=.032\right]$, confirming that load did not impact engagement toward disgust expressions. However, the impact of social anxiety on the engagement bias index was significant $\left[F(1,90)=4.66, p=.034, \eta_{\mathrm{p}}^{2}=.049\right]$. As in the overall analysis, observation of the scatterplots (see Fig. 2) indicated that the engagement bias index decreased with higher levels of social anxiety. In addition, a median split indicated that participants with low social anxiety had an engagement bias index of $10.26 \mathrm{~ms}$, which suggests that they had a bias toward threat, and that participants with high social anxiety had an engagement bias index of $-10.50 \mathrm{~ms}$, indicating a bias away from threat. The raw data are presented in the Appendix.

\section{Disengagement bias}

To analyze the disengagement bias index, a repeated measures ANCOVA was performed with the within-subjects variable of load (no, low, and high) and the continuous predictor variable of social anxiety. Load did not have a significant effect $[F(2$, $\left.91)=0.03, p=.975, \eta_{\mathrm{p}}{ }^{2} \leq .001\right]$, which indicates that the disengagement bias index did not alter across the no-load, low-load, and high-load conditions. In addition, no significant effects were found for social anxiety level $[F(2,91)=0.283, p$ 


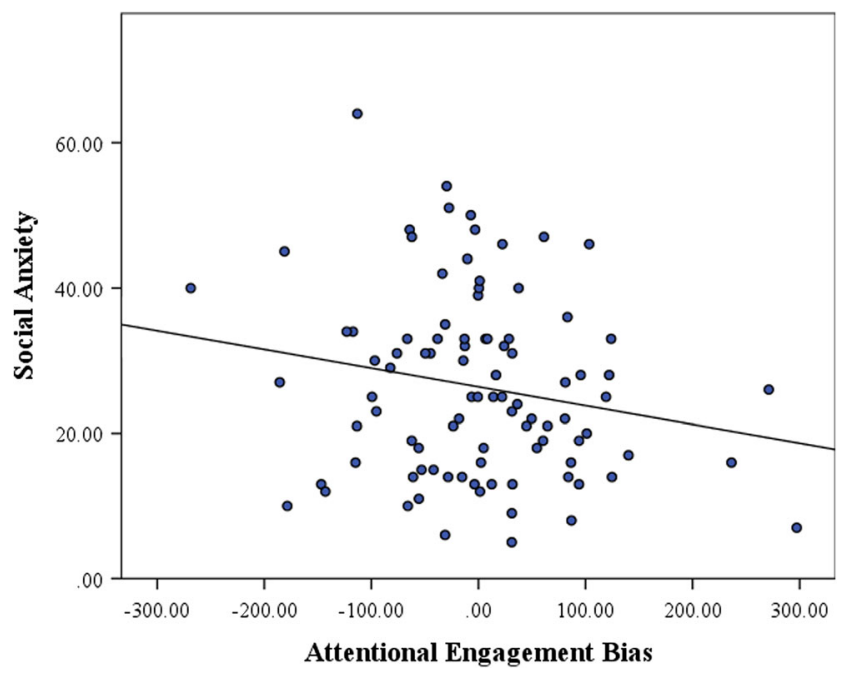

Fig. 2 Relationship between social anxiety and attentional engagement toward threat: engagement bias $=36.44-1.39$ (social anxiety)

$\left.=.596, \eta_{\mathrm{p}}{ }^{2}=.003\right]$ or the interaction between load and social anxiety $\left[F(2,91)=0.95, p=.387, \eta_{\mathrm{p}}{ }^{2}=.010\right]$. This indicates that social anxiety was not associated with difficulty disengaging from disgust facial expressions.

A side note on these results was that, unexpectedly, participants were faster to respond to a probe presented in the distal location $(M=698 \mathrm{~ms})$ than to one in the proximal location $(M$ $=717 \mathrm{~ms})$, relative to the upright image $[F(1,92)=6.06, p=$ $\left..016, \eta_{\mathrm{p}}^{2}=.062\right]$. This suggests that participants had already disengaged from the upright image, for both neutral and disgust expressions, when the probe appeared. The implications of this are addressed in the Discussion.

\section{Discussion}

Despite the proliferation of research exploring attentional biases, the differential roles of bottom-up and top-down attentional mechanisms remain unclear. Using a variation of the dot-probe task, in the present project we aimed to test whether engagement and disengagement biases toward negative facial expressions for individuals with higher levels of social anxiety are driven by top-down attention. Specifically, in the present project we employed a WM load task to manipulate the availability of top-down attentional resources to test whether this impacted attentional biases toward threat.

\section{Do socially anxious individuals have an engagement bias toward threat?}

Surprisingly, this study did not reveal any evidence that individuals with higher social anxiety have an engagement bias toward disgust expressions as compared with neutral expressions. In fact, the study revealed the opposite effect. Although only significant at a trend level $(p=.081)$, the present study showed that increasing levels of social anxiety were associated with a decreased engagement bias. In fact, individuals with high social anxiety were faster to respond to probes following neutral expressions than to those following disgust expressions, indicating a bias away from threat.

We hypothesized that the effects might have become diluted over the course of the experiment due to habituation to threat. The present study included 224 trials per load condition, which totaled 672 trials per participant. Past research had indicated that participants rapidly habituate to emotional faces in the dot-probe task (Staugaard, 2009), which may have accounted for the small effect that was found. To explore this possibility, each participant's first block of trials (totaling 224 trials) was analyzed separately. The trend that was found in the previous analysis was now significant $(p=.034)$, indicating that participants with lower levels of social anxiety had an engagement bias toward the disgust expressions, and participants with high social anxiety had a bias away from the disgust expressions.

These results differ from those in Grafton and MacLeod's (2016) study, which found that socially anxious individuals had an engagement bias toward negative facial expressions. This is surprising, since these two studies aimed to measure the same attentional processes. However, there were some differences in the experimental designs, which might account for these opposing results. In Grafton and MacLeod's (2016) study, they paired negative and neutral faces together on each trial. By contrast, the present study was more similar to the design employed by Grafton and MacLeod (2014) and Rudaizky et al. (2014), who presented the neutral and negative images on separate trials. However, whereas Grafton and MacLeod (2014) and Rudaizky et al. (2014) paired the threat and neutral scenes with an abstract image on each trial, the present study paired negative and neutral faces with their inverted face counterparts to control for low-level visual properties that might capture attention. Any of these methodological differences, either individually or in concert, might be the reason for the contrasting patterns of results.

The lack of threat engagement bias for high socially anxious individuals found in this study reflects the complex nature of attention. For instance, past research has shown enhanced engagement toward threat, delayed disengagement from threat, avoidance of threat, and even no biases at all (see Cisler \& Koster, 2010). Furthermore, research has recently emerged suggesting that anxiety is associated with high variability in attending to threat (Zvielli, Bernstein, \& Koster, 2015). On a dotprobe task, Zvielli et al. (2015) calculated a trial-level bias score by subtracting temporally contiguous pairs of congruent trials (when the probe was presented in the locus of a threatening image) with incongruous trials (when the probe was presented in the locus of a neutral image). This study showed that, as compared to healthy controls, spider phobics had greater variability in attentional capture throughout the experiment, sometimes displaying biases toward spider-related material and sometimes displaying biases away from threat. An average bias 
score across an experiment does not reveal these temporal dynamics. The present bias away from threat could, therefore, reflect the fact that the socially anxious participants tended to avoid the threatening faces for longer (more trials) after initially engaging with the threatening face.

A second possibility is that individuals with high social anxiety were attracted to the threat value of the inverted face. Inverted faces were selected as the paired face in order to control for attentional capture due to low-level perceptual differences across the two presented images. Furthermore, a large body of research has indicated that emotion processing of faces is disrupted by inversion, as the spatial relations of the face are not processed properly (de Gelder, Teunisse, \& Benson, 1997; Searcy \& Bartlett, 1996). However, more recent research has indicated that, although inverted faces are processed in a more piecemeal manner, rapid emotion detection can still occur (Arnold \& Lipp, 2011). As we described previously, the cognitive model of social anxiety posits that individuals with social anxiety are hypervigilant to monitoring their external environment for signs of negative evaluation from others (Rapee \& Heimberg, 1997). In the presence of threat, it is possible that this hypervigilance displayed by socially anxious individuals caused them to monitor the inverted face as well as the upright face. Further research will be needed, therefore, to test whether the lack of engagement bias displayed by highly socially anxious individuals was driven by greater temporal variability or due to the choice of the inverted face as the paired image.

\section{Do socially anxious individuals have a disengagement bias toward threat?}

The present study revealed no evidence that socially anxious individuals have a disengagement bias toward disgust expressions. This is consistent with Grafton and MacLeod's (2016) conclusion that social anxiety is associated with unusual engagement toward threat but not with difficulty disengaging from threat. However, one potential issue with this conclusion is that the present study showed faster RTs for the distal probe position than for the proximal probe position. This means that, on average, when the probe appeared, participants had already disengaged their attention from the position of the target face. It is possible that a briefer presentation time for the faces will be needed to capture a delayed disengagement effect, as the present study employed a presentation time of $500 \mathrm{~ms}$.

A further reason to be hesitant to conclude that socially anxiety is not associated with delayed disengagement is that trait anxiety, which has theoretical underpinnings similar to those of social anxiety, is associated with delayed disengagement from threat (Grafton \& MacLeod, 2014; Rudaizky et al., 2014). For instance, using 500-ms and 1,000-ms presentation times, Rudaizky et al. (2014) paired visual scenes (threatening or neutral) with images of abstract art and found that participants with high trait anxiety had a delayed disengagement bias for threat relative to low trait-anxious participants. It is possible that participants may take longer to process complex visual scenes than faces, therefore taking longer to disengage attention from a visual scene than from a face. Interestingly, Grafton and MacLeod (2014), who utilized a design similar to that of Rudaizky et al. (2014), found delayed disengagement from threat for high traitanxious participants at $100-\mathrm{ms}$ but not at $500-\mathrm{ms}$ stimulus durations. Disengagement effects, therefore, may be more robust for short stimulus presentation times. This indicates that before conclusions about social anxiety and disengagement effects can be made, it will be essential for further research to test these effects at durations shorter than $500 \mathrm{~ms}$.

\section{The effect of WM load on engagement and disengagement biases}

In addition to measuring the engagement and disengagement threat biases associated with social anxiety, with the present study we aimed to test whether these were driven by top-down attention. This study showed no effect of WM load in both the engagement and disengagement analyses. Unfortunately, since a social-anxiety-related disengagement bias toward threat was not found, the impact of WM load on such a bias cannot be determined. However, although the engagement effects were unexpected, an engagement bias toward threat was found for low socially anxious individuals, and a bias away from threat was found for high socially anxious individuals. These results were unaffected by the load manipulation, indicating that they are bottom-up. This result is in accordance with the traditional view that anxiety is associated with an overactive bottom-up threat detection system (Mogg \& Bradley, 1998; Öhman, 2007).

\section{Conclusion and implications}

In sum, the present study indicated that social anxiety is associated with unusual engagement with negative facial expressions. Specifically, participants with high social anxiety had a slight bias away from threat, and participants with low social anxiety had a bias toward threat. This was unaffected by WM load, which indicates that engagement with threat requires few attentional resources and is, therefore, largely driven by bottom-up attention. Social anxiety was not found to be associated with differences in disengagement from threat. Due to mixed findings in the literature, further research will now be needed to clarify the conditions under which high social anxiety is associated with biases either toward or away from threat. In addition, as we discussed previously, further research using shorter presentation times will be needed before concluding that social anxiety is not associated with delayed disengagement from threat.

Acknowledgments This research was supported by an Australian Research Council (ARC) Discovery Early Career Research Award (DE140101734) awarded to S.C.G. 


\section{Appendix Data summary}

Data for the no-load, low-load, and high-load conditions are presented in Tables 2, 3, and 4, respectively. In addi- tion, attentional engagement bias index and disengagement bias index data are presented in Table 5. The low and high social anxiety groups were calculated using a median split.

Table 2. Mean response times (ms) obtained in the no-load condition for low and high social anxiety groups

\begin{tabular}{|c|c|c|c|c|}
\hline Cue Locus & Image Valence & Target Probe Locus & $\begin{array}{l}\text { Low Social Anxiety } \\
M(S D)\end{array}$ & $\begin{array}{l}\text { High Social Anxiety } \\
M(S D)\end{array}$ \\
\hline \multirow{4}{*}{$\begin{array}{l}\text { Distal } \\
\text { (attentional }\end{array}$} & Negative & Distal & $723.24(140.27)$ & $688.49(151.48)$ \\
\hline & als) & Proximal & $696.82(140.87)$ & $656.02(155.37)$ \\
\hline & Neutral & Distal & $731.97(147.31)$ & $692.72(157.55)$ \\
\hline & & Proximal & 691.95 (159.26) & 655.33 (173.96) \\
\hline \multirow{4}{*}{$\begin{array}{l}\text { Proximal } \\
\text { (attentional }\end{array}$} & Negative & Distal & 711.45 (144.62) & $684.94(163.66)$ \\
\hline & trials) & Proximal & $743.72(151.00)$ & $700.86(174.18)$ \\
\hline & Neutral & Distal & $696.83(139.50)$ & $670.15(160.89)$ \\
\hline & & Proximal & $724.91(159.45)$ & $685.95(151.10)$ \\
\hline
\end{tabular}

Table 3. Mean response times (ms) obtained in the low-load condition for low and high social anxiety groups

\begin{tabular}{|c|c|c|c|c|}
\hline Cue Locus & Image Valence & Target Probe Locus & $\begin{array}{l}\text { Low Social Anxiety } \\
M(S D)\end{array}$ & $\begin{array}{l}\text { High Social Anxiety } \\
M(S D)\end{array}$ \\
\hline \multirow{4}{*}{$\begin{array}{l}\text { Distal } \\
\text { (attentional }\end{array}$} & Negative & Distal & $780.42(167.80)$ & $721.12(175.19)$ \\
\hline & $a l s)$ & Proximal & $760.50(168.82)$ & $712.69(207.34)$ \\
\hline & Neutral & Distal & $786.83(179.25)$ & $755.62(216.03)$ \\
\hline & & Proximal & 776.43 (193.29) & $724.63(183.32)$ \\
\hline \multirow{4}{*}{$\begin{array}{l}\text { Proximal } \\
\text { (attentional }\end{array}$} & Negative & Distal & $773.63(181.00)$ & $724.86(191.63)$ \\
\hline & trials) & Proximal & 792.65 (195.46) & $725.72(169.50)$ \\
\hline & Neutral & Distal & $756.25(165.45)$ & $720.51(186.21)$ \\
\hline & & Proximal & $785.41(170.95)$ & 744.75 (184.28) \\
\hline
\end{tabular}

Table 4. Mean response times (ms) obtained in the high-load condition for low and high social anxiety groups

\begin{tabular}{|c|c|c|c|c|}
\hline Cue Locus & Image Valence & Target Probe Locus & $\begin{array}{l}\text { Low Social Anxiety } \\
M(S D)\end{array}$ & $\begin{array}{l}\text { High Social Anxiety } \\
M(S D)\end{array}$ \\
\hline \multirow{4}{*}{$\begin{array}{l}\text { Distal } \\
\text { (attentional }\end{array}$} & Negative & Distal & $712.25(148.15)$ & $649.01(108.89)$ \\
\hline & als) & Proximal & $671.27(144.95)$ & $624.89(112.56)$ \\
\hline & Neutral & Distal & $697.32(150.32)$ & $645.99(108.80)$ \\
\hline & & Proximal & $675.31(143.51)$ & $629.50(103.89)$ \\
\hline \multirow{4}{*}{$\begin{array}{l}\text { Proximal } \\
\text { (attentional }\end{array}$} & Negative & Distal & $680.27(157.41)$ & $634.69(119.23)$ \\
\hline & trials) & Proximal & 708.97 (151.39) & $655.56(118.55)$ \\
\hline & Neutral & Distal & $674.31(134.42)$ & $648.35(130.86)$ \\
\hline & & Proximal & $698.97(153.45)$ & $642.09(126.56)$ \\
\hline
\end{tabular}


Table 5. Means and standard deviations of attentional bias index scores for the three load conditions

\begin{tabular}{llll}
\hline & Load Condition & Engagement Bias & Disengagement Bias \\
\hline Low social anxiety $M(S D)$ & No load & $-13.60(94.07)$ & $-4.19(93.60)$ \\
& Low load & $9.52(112.44)$ & $10.15(80.05)$ \\
High social anxiety $M(S D)$ & High load & $18.98(100.65)$ & $-4.05(124.66)$ \\
& No load & $-4.91(76.92)$ & $-0.12(75.77)$ \\
& Low load & $-22.56(115.26)$ & $23.38(90.77)$ \\
& High load & $7.63(73.38)$ & $-27.12(93.21)$ \\
\hline
\end{tabular}

\section{Appendix Data summary—First block of trials}

Data for the no-load, low-load, and high-load conditions for participants' first block of trials (224 trials) are presented in Tables 6, 7, and 8, respectively. In addition, attentional en- gagement bias index and disengagement bias index data are presented in Table 9. The low and high social anxiety groups were calculated using a median split.

Table 6. Mean response times (ms) obtained in the no-load condition for low and high social anxiety groups for Block 1 of trials

\begin{tabular}{|c|c|c|c|c|}
\hline Cue Locus & Image Valence & Target Probe Locus & Low Social Anxiety $M(S D)$ & High Social Anxiety $M(S D)$ \\
\hline \multirow{4}{*}{$\begin{array}{l}\text { Distal } \\
\text { (attentional }\end{array}$} & Negative & Distal & $710.058(134.71)$ & $799.34(151.82)$ \\
\hline & at trials) & Proximal & $702.54(163.45)$ & $752.71(149.92)$ \\
\hline & Neutral & Distal & $722.72(148.28)$ & $809.19(162.17)$ \\
\hline & & Proximal & $683.19(156.20)$ & $778.05(187.63)$ \\
\hline \multirow{4}{*}{$\begin{array}{l}\text { Proximal } \\
\text { (attentional }\end{array}$} & Negative & Distal & $722.66(168.05)$ & $799.73(152.24)$ \\
\hline & nent trials) & Proximal & $729.73(140.94)$ & $822.73(203.16)$ \\
\hline & Neutral & Distal & $707.75(162.00)$ & $780.81(150.22)$ \\
\hline & & Proximal & $694.61(118.85)$ & $785.94(158.89)$ \\
\hline
\end{tabular}

Table 7. Mean response times (ms) obtained in the low-load condition for low and high social anxiety groups for Block 1 of trials

\begin{tabular}{lllll}
\hline Cue Locus & Image Valence & Target Probe Locus & Low Social Anxiety $M(S D)$ & High Social Anxiety $M(S D)$ \\
\hline Distal & Negative & Distal & $854.28(162.58)$ & $725.13(140.48)$ \\
(attentional engagement trials) & Proximal & $824.28(172.89)$ & $740.04(175.22)$ \\
& Neutral & Distal & $839.20(172.10)$ & $753.05(174.54)$ \\
& & Proximal & $834.99(197.25)$ & $726.63(151.73)$ \\
Proximal & Negative & Distal & $857.06(179.15)$ & $733.91(151.94)$ \\
(attentional disengagement trials $)$ & Proximal & Distal & $861.56(156.94)$ & $741.99(158.85)$ \\
& Neutral & Proximal & $831.80(179.33)$ & $727.39(136.719)$ \\
& & $852.97(167.62)$ & $736.03(163.06)$ \\
\hline
\end{tabular}


Table 8. Mean response times (ms) obtained in the high-load condition for low and high social anxiety groups for Block 1 of trials

\begin{tabular}{|c|c|c|c|c|}
\hline Cue Locus & Image Valence & Target Probe Locus & Low Social Anxiety $M(S D)$ & High Social Anxiety $M(S D)$ \\
\hline \multirow{4}{*}{$\begin{array}{l}\text { Distal } \\
\text { (attentional }\end{array}$} & Negative & Distal & $795.51(94.36)$ & $654.04(83.84)$ \\
\hline & t trials) & Proximal & $729.99(106.39)$ & $645.42(108.40)$ \\
\hline & Neutral & Distal & $783.62(112.04)$ & $658.37(86.81)$ \\
\hline & & Proximal & $767.76(95.05)$ & $643.53(104.24)$ \\
\hline \multirow{4}{*}{$\begin{array}{l}\text { Proximal } \\
\text { (attentional }\end{array}$} & Negative & Distal & $756.83(124.60)$ & $652.17(108.39)$ \\
\hline & nent trials) & Proximal & $784.69(108.30)$ & $678.97(91.45)$ \\
\hline & Neutral & Distal & $717.69(89.50)$ & $674.93(115.75)$ \\
\hline & & Proximal & 785.98 (145.19) & $660.09(98.46)$ \\
\hline
\end{tabular}

Table 9. Means and standard deviations of attentional bias index scores for the three load conditions for Block 1 of trials

\begin{tabular}{|c|c|c|c|}
\hline & Load Condition & Engagement Bias & Disengagement Bias \\
\hline \multirow[t]{3}{*}{ Low social anxiety $M(S D)$} & No load & $-32.01(60.84)$ & $-20.21(66.91)$ \\
\hline & Low load & $25.80(107.87)$ & $16.68(87.76)$ \\
\hline & High load & $49.66(92.51)$ & $40.44(160.04)$ \\
\hline \multirow[t]{3}{*}{ High social anxiety $M(S D)$} & No load & $-15.49(100.77)$ & $-17.88(81.02)$ \\
\hline & Low load & $-41.34(99.16)$ & $0.56(105.43)$ \\
\hline & High load & $-6.22(69.05)$ & $-41.65(69.21)$ \\
\hline
\end{tabular}

\section{References}

Arnold, D. H., \& Lipp, O. V. (2011). Discrepant integration times for upright and inverted faces. Perception, 40, 989-999. https://doi. org/10.1068/p6955

Bar-Haim, Y. (2010). Attention bias modification (ABM): A novel treatment for anxiety disorders. Journal of Child Psychology and Psychiatry, 51, 859-870. https://doi.org/10.1111/j.1469-7610.2010. 02251.x

Brainard, D. H. (1997). The Psychophysics Toolbox. Spatial Vision, 10, 433-436. https://doi.org/10.1163/156856897X00357

Breiter, H. C., Etcoff, N. L., Whalen, P. J., Kennedy, W. A., Rauch, S. L., Buckner, R. L., ... \& Rosen, B. R. (1996). Response and habituation of the human amygdala during visual processing of facial expression. Neuron, 17, 875-887. https://doi.org/10.1016/S0896-6273(00) 80219-6

Cisler, J. M., \& Koster, E. H. (2010). Mechanisms of attentional biases towards threat in anxiety disorders: An integrative review. Clinical Psychology Review, 30, 203-216. https://doi.org/10.1016/j.cpr. 2009.11.003

Corbetta, M., \& Shulman, G. L. (2002). Control of goal-directed and stimulus-driven attention in the brain. Nature Reviews Neuroscience, 3, 201-215. https://doi.org/10.1038/Nrn755

de Fockert, J. W., Rees, G., Frith, C. D., \& Lavie, N. (2001). The role of working memory in visual selective attention. Science, 291, 18031806. https://doi.org/10.1126/science.1056496

de Gelder, B., Teunisse, J.-P., \& Benson, P. J. (1997). Categorical perception of facial expressions: Categories and their internal structure. Cognition and Emotion, 11, 1-23. https://doi.org/10.1080/ 026999397380005
Desimone, R., \& Duncan, J. (1995). Neural mechanisms of selective visual attention. Annual Review of Neuroscience, 18, 193-222. https://doi.org/10.1146/annurev.ne.18.030195. 001205

Eastwood, J. D., Smilek, D., \& Merikle, P. M. (2001). Differential attentional guidance by unattended faces expressing positive and negative emotion. Perception \& Psychophysics, 63, 1004-1013. https:// doi.org/10.3758/BF03194519

Ebner, N. C., Riediger, M., Lindenberger, U. (2010). FACES-A database of facial expressions in young, middle-aged, and older women and men: Development and validation. Behavior Research Methods, 42, 351-362. https://doi.org/10. 3758/BRM.42.1.351

Gilboa-Schechtman, E., Foa, E. B., \& Amir, N. (1999). Attentional biases for facial expressions in social phobia: The face-in-the-crowd paradigm. Cognition and Emotion, 13, 305-318. https://doi.org/10. 1080/026999399379294

Grafton, B., \& MacLeod, C. (2014). Enhanced probing of attentional bias: The independence of anxiety-linked selectivity in attentional engagement with and disengagement from negative information. Cognition and Emotion, 28, 1287-1302. https://oi.org/10.1080/ 02699931.2014 .881326

Grafton, B., \& MacLeod, C. (2016). Engaging with the wrong people: The basis of selective attention to negative faces in social anxiety. Clinical Psychological Science, 4, 793-804. https://doi.org/10. 1177/2167702615616344

Heimberg, R. G., Mueller, G. P., Holt, C. S., Hope, D. A., \& Liebowitz, M. R. (1992). Assessment of anxiety in social-interaction and being observed by others: The social-interaction anxiety scale and the social phobia scale. Behavior Therapy, 23, 53-73. https://doi.org/ 10.1016/S0005-7894(05)80308-9 
Jonides, J. (1981). Voluntary versus automatic control over the mind's eye's movement. In J. B. Long \& A. D. Baddeley (Eds.), Attention and performance IX (pp. 187-203). Hillsdale: Erlbaum.

Judah, M. R., Grant, D. M., Lechner, W. V., \& Mills, A. C. (2013). Working memory load moderates late attentional bias in social anxiety. Cognition and Emotion, 27, 502-511. https://doi.org/10.1080/ 02699931.2012.719490

Kastner, S., \& Pinsk, M. A. (2004). Visual attention as a multilevel selection process. Cognitive, Affective, \& Behavioral Neuroscience, 4 , 483-500. https://doi.org/10.3758/CABN.4.4.483

Kenrick, D. T., Neuberg, S. L., Griskevicius, V., Becker, D. V., \& Schaller, M. (2010). Goal-driven cognition and functional behavior: The fundamental-motives framework. Current Directions in Psychological Science, 19, 63-67. https://doi.org/10.1177/ 0963721409359281

Lang, P. J., Bradley, M. M., \& Cuthbert, B. N. (1997). Motivated attention: Affect, activation and action. In P. J. Lang, R. F. Simons, \& M. T. Balaban (Eds.), Attention and orienting: Sensory and motivational processes (pp. 97-135). Hillsdale: Erlbaum.

LeDoux, J. E. (1996). The emotional brain: The mysterious underpinnings of emotional life. New York: Simon \& Schuster.

LoBue, V. (2014). Deconstructing the snake: The relative roles of perception, cognition, and emotion on threat detection. Emotion, 14, 701711. https://doi.org/10.1037/a0035898

LoBue, V., \& DeLoache, J. S. (2011). What's so special about slithering serpents? Children and adults rapidly detect snakes based on their simple features. Visual Cognition, 19, 129-143. https://doi.org/10. 1080/13506285.2010.522216

LoBue, V., \& Larson, C. L. (2010). What makes an angry face look so ... angry? Examining visual attention to the shape of threat in children and adults. Visual Cognition, 18, 1165-1178. https://doi.org/10. 1080/13506281003783675

LoBue, V., Rakison, D. H., \& DeLoache, J. S. (2010). Threat perception across the life span: Evidence for multiple converging pathways. Current Directions in Psychological Science, 19, 375-379. https:// doi.org/10.1177/0963721410388801

Lovibond, S. H., \& Lovibond, P. F. (1995). Manual for the depression anxiety stress scales. Sydney: Psychology Foundation.

Mattick, R. P., \& Clarke, J. C. (1989). Development and validation of measures of social phobia scrutiny fear and social interaction anxiety. Unpublished manuscript.

McNeil, D. W. (2010). Evolution of terminology and constructs in social anxiety and its disorders. In S. G. Hofmann \& P. M. DiBartolo (Eds.), Social anxiety: Clinical, developmental, and social perspectives (2nd ed., Vol. 2, pp. 3-21). San Diego: Academic Press.

Mogg, K., \& Bradley, B. P. (1998). A cognitive-motivational analysis of anxiety. Behaviour Research and Therapy, 36, 809-848. https://doi. org/10.1016/S0005-7967(98)00063-1

Mogg, K., Philippot, P., \& Bradley, B. P. (2004). Selective attention to angry faces in clinical social phobia. Journal of Abnormal Psychology, 113, 160-165. https://doi.org/10.1037/0021-843x.113. 1.160

Öhman, A. (2007). Has evolution primed humans to "beware the beast"? Proceedings of the National Academy of Sciences, 104, 1639616397. https://doi.org/10.1073/pnas.0707885104

Öhman, A., Lundqvist, D., \& Esteves, F. (2001). The face in the crowd revisited: A threat advantage with schematic stimuli. Journal of
Personality and Social Psychology, 80, 381-396. https://doi.org/ 10.1037/0022-3514.80.3.381

Pessoa, L., McKenna, M., Gutierrez, E., \& Ungerleider, L. G. (2002). Neural processing of emotional faces requires attention. Proceedings of the National Academy of Sciences, 99, 1145811463. https://doi.org/10.1073/pnas.172403899

Pishyar, R., Harris, L. M., \& Menzies, R. G. (2004). Attentional bias for words and faces in social anxiety. Anxiety, Stress, and Coping, 17, 23-36. https://doi.org/10.1080/10615800310001601458

Posner, M. I. (1980). Orienting of attention. Quarterly Journal of Experimental Psychology, 32, 3-25. https://doi.org/10.1080/ 00335558008248231

Pratto, F., \& John, O. P. (1991). Automatic vigilance: The attentiongrabbing power of negative social information. Journal of Personality and Social Psychology, 61, 380-391. https://doi.org/ 10.1037/0022-3514.61.3.380

Rapee, R. M., \& Heimberg, R. G. (1997). A cognitive-behavioral model of anxiety in social phobia. Behaviour Research and Therapy, 35, 741-756. https://doi.org/10.1016/S0005-7967(97)00022-3

Rhodes, M. G., \& Anastasi, J. S. (2012). The own-age bias in face recognition: A meta-analytic and theoretical review. Psychological Bulletin, 138, 146-174. https://doi.org/10.1037/a0025750

Rudaizky, D., Basanovic, J., \& MacLeod, C. (2014). Biased attentional engagement with, and disengagement from, negative information: Independent cognitive pathways to anxiety vulnerability? Cognition and Emotion, 28, 245-259. https://doi.org/10.1080/02699931.2013. 815154

Searcy, J. H., \& Bartlett, J. C. (1996). Inversion and processing of component and spatial-relational information in faces. Journal of Experimental Psychology: Human Perception and Performance, 22, 904-915. https://doi.org/10.1037/0096-1523.22.4.904

Shechner, T., Britton, J. C., Perez-Edgar, K., Bar-Haim, Y., Ernst, M., Fox, N. A., ... \& Pine, D. S. (2012). Attention biases, anxiety, and development: Toward or away from threats or rewards? Depression and Anxiety, 29, 282-294. https://doi.org/10.1002/da.20914

Spielberger, C. D., Gorsuch, R. L., Lushene, R., Vagg, P. R., \& Jacobs, G. A. (1983). Manual for the State-Trait Anxiety Inventory. Palo Alto: Consulting Psychologist Press.

Staugaard, S. R. (2009). Reliability of two versions of the dot-probe task using photographic faces. Psychology Science Quarterly, 51, 339 350.

Treisman, A. M., \& Gelade, G. (1980). A feature-integration theory of attention. Cognitive Psychology, 12, 97-136. https://doi.org/10. 1016/0010-0285(80)90005-5

Van Dillen, L. F., \& Koole, S. L. (2009). How automatic is "automatic vigilance"? The role of working memory in attentional interference of negative information. Cognition and Emotion, 23, 1106-1117. https://doi.org/10.1080/02699930802338178

Vuilleumier, P., \& Righart, R. (2011). Attention and automaticity in processing facial expressions. In A. Calder, G. Rhodes, M. Johnson, \& J. Haxby (Eds.), The Oxford handbook of face perception (pp. 449478). Oxford: Oxford University Press.

Zvielli, A., Bernstein, A., \& Koster, E. H. (2015). Temporal dynamics of attentional bias. Clinical Psychological Science, 3, 772-788. https:// doi.org/10.1177/2167702614551572 